\title{
A profile of patients presenting at a low vision clinic in a resource-limited setting
}

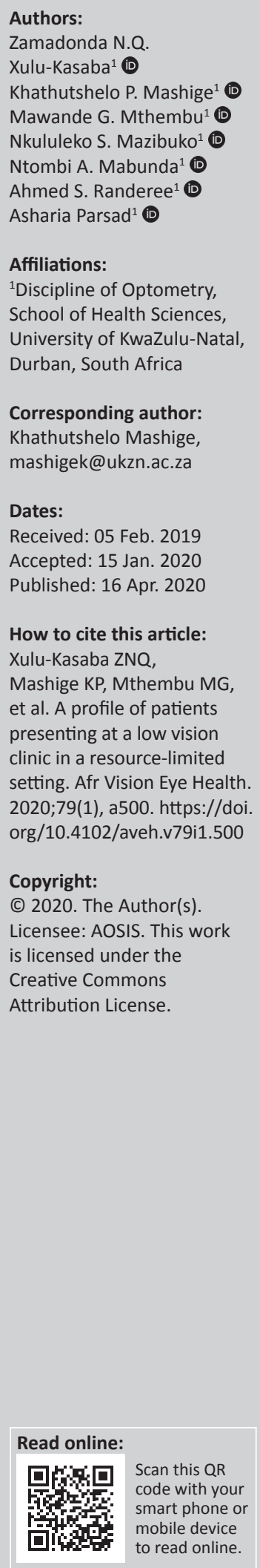

Background: The university-based low vision clinic is one of the few low vision clinics in South Africa.

Aim: To describe demographic and clinical profiles of patients who attended this clinic from 2010 to 2017

Setting: The university low vision clinic, South Africa.

Methods: The record cards of all patients seen at the low vision clinic over 8 years were examined and the following information was extracted: age, gender, presenting visual acuity (VA), VA following low vision assessment, cause of visual impairment and types of low vision devices recommended.

Results: A total of 621 patients were examined, comprising $45.1 \%$ males and $55.9 \%$ females aged $36.0 \pm 18.2$ years (range: $4-93$ years). Many of these patients $(33.7 \%)$ had presenting VA worse than 1.3 logarithm of the Minimum Angle of Resolution $(\log$ MAR) $(>6 / 120)$ at $4 \mathrm{~m}$ in the better eye, and 196 (31.6\%) had presenting VA of worse than $1.3 \log$ MAR at near distance. Following optical low vision assessment, $62.4 \%$ had distance VA of 0.9 LogMAR (6/48) to $-0.2 \log$ MAR $(6 / 3.8)$ and $58.4 \%$ had near VA of $0.9 \operatorname{logMAR}(6 / 48)$ to $-0.2 \log$ MAR $(6 / 3.8)$. Albinism (22.7\%), unknown causes (18.2\%), cataract (15.5\%) and macular diseases (12.2\%) were the most common causes of low vision. Amblyopia $(80.7 \%)$ was the most common cause of low vision in patients aged 20 years and younger, followed by albinism $(68.1 \%)$ and corneal diseases $(41 \%)$. Cataract $(78.1 \%)$, macular diseases $(64.4 \%)$ and glaucoma $(55.9 \%)$ were the most common causes of low vision in patients aged more than 60 years. Telescopes (33.8\%) were the most commonly recommended form of intervention, followed by magnifiers $(29.6 \%)$ and protective measures $(24.5 \%)$.

Conclusion: Albinism, cataract and macular diseases are the predominant causes of low vision in patients attending this low vision clinic. There was a significant improvement in VA after low-vision assessment, particularly for patients with presenting VA of better than $1.3 \log$ MAR $(6 / 120)$.

Keywords: low vision; amblyopia; cataract; macular diseases; glaucoma; telescopes; magnifiers.

\section{Introduction}

The World Health Organization (WHO) defines low vision as 'visual acuity [VA] less than 6/18 and equal to or better than $3 / 60$ in the better eye with [the] best correction' and a person with low vision as:

$[O]$ ne who has impairment even after treatment and/or standard refractive correction, and has a visual acuity of less than $6 / 18$ to light perception, or a visual field less than 10 degrees from the point of fixation, but who uses, or is potentially able to use, vision for the planning and/or execution of a task for which vision is essential. ${ }^{1}$

The WHO International Classification of Diseases (ICD)-10 categories of visual loss define low vision as 'a corrected visual acuity (VA) in the better eye of $6 / 18$ down to and including $3 / 60{ }^{2}{ }^{2}$ This definition includes all individuals regardless of the cause of visual loss. The WHO recently suggested that 'presenting visual acuity' (VA tested with distance spectacles if usually worn), as well as uncorrected VA, be used in all population-based surveys. ${ }^{2}$ The new definition emanated from the fact that the ICD-10 categories of visual loss do not allow refractive errors to be assessed as a cause of visual impairment (VI). Most individuals having a presenting VA of $6 / 18$ in the better eye down to and including 3/60 require correction (such as cataract 
surgery) or other treatment to restore sight and thus do not require assessment for low-vision interventions (including optical devices). ${ }^{2}$

It is estimated that the number of people with VI worldwide is approximately 1.3 billion, of which 246 million have low vision and 36 million are blind. ${ }^{3}$ Globally, the leading causes of VI are uncorrected refractive errors and cataract. ${ }^{3}$ Other major causes of VI are, in order of importance, glaucoma, agerelated macular degeneration, diabetic retinopathy and trachoma. ${ }^{3}$ Approximately $80 \%$ of all VI globally is considered avoidable, and the majority of people with VI are aged 50 years and older. ${ }^{3}$ The impact of VI has important health, socio-economic and quality of life (QoL) implications. ${ }^{4,5}$ The least developed countries of the world carry the largest burden of VI, and this burden is also unequally distributed across age groups, being largely confined to adults aged 50 years and more. A gender discordance is also found regarding VI, with females having a significantly higher risk of having VI than males. ${ }^{4,5}$

Richard ${ }^{6}$ conducted a prospective study amongst new consecutive patients presenting at the eye clinic of Niger Delta University Teaching Hospital, Nigeria, to provide baseline data on the causes of blindness and low vision. The study showed that cataract was responsible for $63 \%$ of blindness and $49.8 \%$ of low vision whilst glaucoma accounted for $22 \%$ of blindness and $17.9 \%$ of low vision. The author concluded that the majority of blindness was avoidable (93.5\%) and found in the fifth and sixth decades of life. A similar study by Ogbonnaya ${ }^{7}$ described the causes of blindness amongst patients seen at the eye clinic of Ebonyi State University Teaching Hospital, Abakaliki, Nigeria. The results showed that cataract (43\%) and glaucoma (42\%) were the commonest causes of blindness in their study population. The authors concluded that there was a need for further studies to elicit the factors responsible for the prevalence of these figures. In a prospective crosssectional study, Olusanya et al. ${ }^{8}$ described the characteristics of 193 patients attending the low vision clinic of a Nigerian tertiary hospital over a 36-month period. The age of the patients ranged between 6 and 90 years and the majority (58\%) were aged below 50 years. The commonest cause of low vision was retinitis pigmentosa $(16.6 \%) ; 14.5 \%$ had agerelated macular degeneration (ARMD); 9.8\% had albinism whilst only $1 \%$ had diabetic retinopathy. Age-related macular degeneration (45.2\%) was the commonest cause in the elderly patients whilst albinism (24.4\%) and optic atrophy $(24.4 \%)$ were the commonest cause in children.

A recent study to identify causes of low vision in the patients of the eye clinic at the University of Nigeria Teaching Hospital (UNTH) showed that glaucoma (36\%) and oculocutaneous albinism (14.7\%) were the main causes of low vision. ${ }^{9}$ A retrospective study of 604 patients managed at the low vision centre of the Korle Bu Teaching Hospital in Ghana showed that glaucoma was the leading cause of low vision in 135 (22.35\%) patients, followed by non-glaucomatous optic atrophy in $62(10.26 \%)$, retinitis pigmentosa in $54(8.94 \%)$, maculopathy in $52(8.61 \%)$ and ARMD in $48(7.95 \%)$ patients. The study also showed that magnifiers and telescopes were the most commonly prescribed devices. ${ }^{10}$ Ansah ${ }^{11}$ had reported that cataract, refractive error and glaucoma were the leading causes of VI whilst glaucoma and cataract caused blindness in most of the patients in Juaben Hospital Eye clinic, Ghana.

In South Africa, limited data are available on the prevalence of VI and blindness. A rapid assessment of an avoidable blindness study conducted in the province of KwaZuluNatal showed that the prevalence of blindness was $1.9 \%$ whilst the prevalence of severe and moderate VI was $1.2 \%$ and $3.9 \%$, respectively..$^{12}$ According to this study, the causes of VI included cataracts, glaucoma and diabetic retinopathy. KwaZulu-Natal is one of the provinces in South Africa, and approximately one-fifth of the total population of the country live in this province. The University of KwaZuluNatal (UKZN) eye clinic is situated on the western end from the city centre of Durban. The clinic provides students studying optometry with an opportunity to gain practical experience and to attain professional minimum competencies as stipulated by the Professional Board of Optometry and Dispensing Opticians (PBODO). In addition, the clinic serves the visual needs of the population of the greater Durban and other areas of KwaZulu-Natal that have limited access to eye care. The clinic provides general, contact lenses, paediatric, binocular vision and low vision eye care services. Limited information is available on the profile of patients attending this universitybased low vision clinic. It is important to have such information, as this helps in planning and implementing low vision services that meet the needs of the patients accessing this clinic.

Anecdotal evidence from the UKZN low vision clinic also suggests that a high number of patients who attend this clinic are referred in spite of not meeting the presenting VA stipulation for low vision. This leads to over referral of patients to this clinic. In addition, clinical studies give more detailed information on patients actually attending low vision clinics. To the best of the authors' knowledge, there are no previous reports of such clinical studies from South Africa, as there are very few low vision centres available in the country.

\section{Methods \\ Study design}

This is a retrospective study of low vision patients examined at the low vision clinic of the university from January 2010 to December 2017.

\section{Procedures}

The study used a specially designed data-collection sheet to collect information related to the study variables. The variables included demographic and clinical characteristics 
as well as recommended management interventions. For standardisation, only one researcher was responsible for extracting and recording data from record cards. All data were double-checked against record cards to ensure accuracy 1 week after the data were captured. Patient cards that were signed by the clinical supervisor and contained demographic and clinical information were considered for inclusion in this study. The details of the low-vision ocular examination included information on the primary reason for presenting at the UKZN clinic, source of referral, presenting VA at distance and near, VA with the low-vision assistive device, the cause of low vision and the type of low-vision assistive devices (optical and non-optical) recommended. Patient cards that were not signed by the clinical supervisor were excluded from the study. Whenever data related to any of the study variables were not present on the card, it was recorded as missing.

\section{Statistical analysis}

Low vision cards were arranged into years, and data were extracted and recorded onto an Excel spreadsheet. The Statistical Package for Social Sciences (SPSS), version 24, was used for analysis. Demographic characteristics and clinical characteristics of patients seen at the low vision clinic as well as interventions recommended were identified and analysed using frequency tables and percentages. Significant differences in mean age, gender and VA were determined using independent-samples $t$-test, and the $p$-value $<0.05$ was considered significant.

\section{Ethical considerations}

The study was approved by the University of KwaZuluNatal's Biomedical Research Ethics Committee (BREC, Ref No.: BE324/18). Permission to access low vision records was obtained from the Academic Leader of the Discipline of Optometry of the University of KwaZulu-Natal.

\section{Results}

\section{Demographic characteristics}

A total of 621 cards of the patients seen at the low vision clinic were reviewed. Of these, 341 (54.9\%) were of females and $280(45.1 \%)$ were of males. The difference between the proportion of males and females was statistically significant $(p<0.05)$. The mean age of the patients was $36.0 \pm 18.2$ years (age range: $4-93$ years) and the median age was 33 years. There were $204(32.9 \%)$ patients in the 0-20 age group and $142(22.9 \%)$ were older than 60 years (Table 1).

In all, $165(26.6 \%)$ patients were referred from the special education schools that catered to the needs of learners with VI and those with multiple disabilities, 288 (46.4\%) were referred from the local hospitals, 147 (23.7\%) from private optometry practices and $21(3.4 \%)$ were referred from the KwaZulu-Natal Blind and Deaf Society. All the patients presented with the main complaint of poor vision.
TABLE 1: Age and gender distribution of patients seen at the low vision clinic of the Department of Optometry, University of KwaZulu-Natal.

\begin{tabular}{|c|c|c|c|c|c|c|}
\hline \multirow{2}{*}{$\begin{array}{l}\text { Age group } \\
\text { (years) }\end{array}$} & \multicolumn{2}{|c|}{ Female } & \multicolumn{2}{|c|}{ Male } & \multicolumn{2}{|c|}{ Total } \\
\hline & $n$ & $\%$ & $n$ & $\%$ & $n$ & $\%$ \\
\hline $0-20$ & 114 & 55.9 & 90 & 44.1 & 204 & 32.9 \\
\hline $21-50$ & 70 & 57.9 & 51 & 42.1 & 121 & 19.5 \\
\hline $51-60$ & 86 & 55.8 & 68 & 44.2 & 154 & 24.8 \\
\hline$>60$ & 77 & 54.2 & 65 & 45.8 & 142 & 22.8 \\
\hline Total & 347 & 54.9 & 274 & 45.1 & 621 & 100 \\
\hline
\end{tabular}

\section{Visual profile}

A total of 209 patients (33.7\%) had presenting VA worse than 1.3 logarithm of the Minimum Angle of Resolution $(\log M A R)(>6 / 120)$ at $4 \mathrm{~m}$ in the better eye and $196(31.6 \%)$ had presenting VA of worse than $1.3 \log$ MAR at near distance (Table 2). The mean distance VA obtained after refraction was $1.0 \log$ MAR (6/60). Following optical low-vision assessment, $62.4 \%$ had distance VA of $0.9 \log$ MAR $(6 / 48)$ to $-0.2 \log$ MAR $(6 / 3.8)$ (Table 2). The mean distance VA was $0.8 \log$ MAR $(6 / 38)$, and this was significantly better $(p<0.05)$ statistically compared with the mean values of both presenting VA and VA after refraction. Most patients (86.6\%) with distance VA of worse than $1.3 \log$ MAR $(6 / 120)$ did not show any VA improvement after low-vision assessment. However, $73.3 \%$ of the patients with VA of 1.0-1.3 logMAR had an average VA improvement of seven lines to $0.5 \log$ MAR, and $70.6 \%$ of those with VA of 0.9-0.5 $\log$ MAR had an average VA improvement of three lines to $0.4 \log M A R$.

The mean VA after optical low-vision assessment was $0.8 \log$ MAR, which was significantly better statistically compared with the mean presenting near VA (Table 2). The majority $(93.8 \%)$ of patients with near VA of worse than $1.3 \log$ MAR did not have any near vision improvement, and $6.2 \%$ had an average VA improvement to $0.9 \log$ MAR. A high proportion $(69.2 \%)$ of patients with near VA ranging from $0.4 \log$ MAR to $0.1 \log$ MAR had an average VA improvement of two lines with the final VA of $0.0 \log$ MAR.

\section{Causes of low vision}

The causes of low vision in the study population were albinism $(22.7 \%)$, followed by unknown causes $(18.2 \%)$, cataract (15.5\%) and macula diseases (12.2\%) (Table 3).

In the age category of $0-20$ years, the most common causes of low vision were amblyopia (80.7\%), albinism (68.1\%) and corneal diseases $(41 \%)$. Cataracts $(78.1 \%)$, macular diseases $(64.4 \%)$ and glaucoma (55.9\%) were the most common causes in patients aged $>60$ years. The causes of low vision in patients in different age groups are given in Table 4 .

\section{Management interventions recommended}

Telescopes were recommended to 210 (33.8\%) patients and magnifiers to $184(29.6 \%)$ patients, whilst non-optical devices, such as sunglasses or hats, were recommended to 152 (24.5\%) patients (Table 5). 
TABLE 2: Presenting visual acuity in the better eye and also after correction with a low vision device.

\begin{tabular}{|c|c|c|c|c|c|c|c|c|}
\hline \multirow[t]{2}{*}{ Variables } & \multicolumn{4}{|c|}{ Presenting VA in the better eye } & \multicolumn{4}{|c|}{ VA after correction with a low device } \\
\hline & VA (logMAR) & VA (Snellen) & $n$ & $\%$ & VA (logMAR) & VA (Snellen) & $n$ & $\%$ \\
\hline \multicolumn{9}{|l|}{ Distance } \\
\hline & $>1.3$ & $>6 / 120$ & 209 & 33.7 & $>1.3$ & $>6 / 120$ & 181 & 29.1 \\
\hline & $1.3-1.0$ & $6 / 120-6 / 60$ & 175 & 28.2 & $1.3-1.0$ & $6 / 120-6 / 60$ & 53 & 8.5 \\
\hline & $0.9-0.5$ & $6 / 48-6 / 19$ & 168 & 27.0 & $0.9-0.5$ & $6 / 48-6 / 19$ & 142 & 22.9 \\
\hline & $0.4-0.1$ & $6 / 15-6 / 7.5$ & 0 & 0.0 & $0.4-0.1$ & $6 / 15-6 / 7.5$ & 118 & 19.0 \\
\hline & $0.0--0.2$ & $6 / 6-6 / 3.8$ & 69 & 11.1 & $0.0--0.2$ & $6 / 6-6 / 3.8$ & 127 & 20.5 \\
\hline & Total & - & 621 & 621 & - & - & 621 & 100.0 \\
\hline \multicolumn{9}{|l|}{ Near } \\
\hline & $>1.3$ & $>6 / 120$ & 196 & 31.6 & $>1.3$ & $>6 / 120$ & 168 & 27.1 \\
\hline & $1.3-1.0$ & $6 / 120-6 / 60$ & 162 & 26.1 & $1.3-1.0$ & $6 / 120-6 / 60$ & 90 & 14.5 \\
\hline & $0.9-0.5$ & $6 / 48-6 / 19$ & 141 & 22.7 & $0.9-0.5$ & $6 / 48-6 / 19$ & 82 & 13.2 \\
\hline & $0.4-0.1$ & $6 / 15-6 / 7.5$ & 62 & 9.9 & $0.4-0.1$ & $6 / 15-6 / 7.5$ & 206 & 33.2 \\
\hline & $0.0-0.2$ & $6 / 6-6 / 3.8$ & 60 & 9.7 & $0.0--0.2$ & $6 / 6-6 / 3.8$ & 75 & 12.0 \\
\hline
\end{tabular}

Note: A significant proportion of patients had presenting visual acuity that did not fall into the stipulation for low vision.

$\mathrm{VA}$, visual acuity.

TABLE 3: Causes of low vision in 621 patients attending the low vision clinic, Department of Optometry, University of KwaZulu-Natal, from January 2010 to December 2017.

\begin{tabular}{lcc}
\hline Condition & Number $(\boldsymbol{n})$ & Frequency (\%) \\
\hline Albinism & 141 & 22.7 \\
Cataract & 96 & 15.5 \\
Macular diseases & 76 & 12.2 \\
Amblyopia & 57 & 9.2 \\
Corneal diseases & 39 & 6.3 \\
Non-glaucomatous optic atrophy & 38 & 6.1 \\
Glaucoma & 34 & 5.5 \\
Diabetic retinopathy & 15 & 2.4 \\
Hypertensive retinopathy & 9 & 1.4 \\
Retinitis pigmentosa & 3 & 0.5 \\
Unknown & 113 & 18.2 \\
\hline Total & $\mathbf{6 2 1}$ & $\mathbf{1 0 0 . 0}$ \\
\hline
\end{tabular}

\section{Discussion}

Profiles of low-vision patients have been studied extensively in different countries and reported in many publications. $6,7,8,9,10,11,12,13,14,15,16,17,18,19,20,21,22,23,24,25$ These studies have used information from one or a few low vision clinics, from questionnaire reports or from blindness registration data to provide detailed information regarding the profiles of low-vision patients. Low-vision clinic-based studies provide reliable and usually detailed ophthalmic information about low-vision patients when compared with population surveys, blind school studies or blind register studies. ${ }^{18,19}$ However, the disadvantage of data from studies of low vision clinic is as follows:

[T] hey are often collected from small and preselected populations of patients from isolated clinics; thus, their value is limited because of possible sampling errors and are limited in their extrapolation to the general population. ${ }^{20}$

Nonetheless, the information obtained from such studies is important for planning low-vision services in those settings. ${ }^{17}$ Similar studies have not been conducted in South Africa. This article reports the results of a retrospective study of 621 patients seen at a low vision clinic of a university in South Africa. Except for the gender profile, the results found in this study are comparable to those found in developing countries but differ from those found in developed countries.

The rate of low vision and blindness is known to increase with age. ${ }^{17}$ However, in this study, the mean age of patients presenting at the low vision clinic was $36 \pm 18.2$ years (range: 4-93 years), and $52.4 \%$ of the patients were aged 50 years or younger whilst $22.8 \%$ were aged more than 60 years. There was a statistically significant difference between the mean ages in both sexes $(p<0.05)$. In South Africa, young people aged between 15 and 34 years make up $35.7 \%$ of the total population and those aged 65 years and above constitute only $5.6 \%$ of the total population. ${ }^{26} \mathrm{~A}$ fewer number of patients aged $>60$ years could also be because of general lower life expectancy (61.1 years for males and 67.3 years for females) in the country. ${ }^{26}$

The age distribution of patients presenting at a low vision clinic in this study is different from previous reports from developed countries but is similar to those from other developing countries. For example, a younger population of low-vision patients was reported by Ackuaku-Dogbe et al. ${ }^{10}$ in Ghana, in which the median age was 38 years. Other studies $8,9,21,22,23$ from developing countries have reported high proportions of low-vision patients aged below 50 years and low proportion of low-vision patients aged 60 years and above. In contrast, studies ${ }^{18,19,24}$ from developed countries reported high proportions of lowvision patients aged 60 years and above. For instance, in Australia, Wolffsohn and Cochrane ${ }^{19}$ reported that $87 \%$ of the patients in their study were aged 60 years and above. The discrepancy in the pattern of age distribution may be an indication of the differences in the life expectancy between developing and developed countries, with low life expectancy in developing countries. ${ }^{23}$ It is also possible that older persons in developing countries have poor access to low-vision services than those in developed countries because of reasons such as lower levels of literacy, amongst others. ${ }^{8}$ 
TABLE 4: Causes of low vision in different age groups of 621 patients presenting at the low vision clinic of the Department of Optometry, University of KwaZulu-Natal.

\begin{tabular}{|c|c|c|c|c|c|c|c|c|c|c|}
\hline \multirow[t]{2}{*}{ Condition } & \multicolumn{2}{|c|}{$0-20$} & \multicolumn{2}{|c|}{$21-50$} & \multicolumn{2}{|c|}{$51-60$} & \multicolumn{2}{|c|}{$>60$} & \multicolumn{2}{|c|}{ Total } \\
\hline & $n$ & $\%$ & $n$ & $\%$ & $n$ & $\%$ & $n$ & $\%$ & $n$ & $\%$ \\
\hline Albinism & 96 & 68.1 & 43 & 30.5 & 2 & 1.4 & 0 & 0.0 & 141 & 100.0 \\
\hline Unknown & 16 & 14.2 & 26 & 23.0 & 29 & 25.7 & 42 & 37.1 & 113 & 100.0 \\
\hline Cataract & 6 & 6.3 & 0 & 0.0 & 15 & 15.7 & 75 & 78.1 & 96 & 100.0 \\
\hline Macular diseases & 5 & 6.6 & 3 & 3.9 & 19 & 14.5 & 49 & 64.4 & 76 & 100.0 \\
\hline Amblyopia & 46 & 80.7 & 11 & 19.3 & 0 & 0.0 & 0 & 0.0 & 57 & 100.0 \\
\hline Corneal diseases & 16 & 41.0 & 11 & 28.2 & 8 & 20.5 & 4 & 10.3 & 39 & 100.0 \\
\hline Non-glaucomatous optic atrophy & 5 & 13.2 & 7 & 18.4 & 15 & 39.5 & 11 & 28.9 & 38 & 100.0 \\
\hline Glaucoma & 0 & 0.0 & 2 & 5.9 & 13 & 38.2 & 19 & 55.9 & 34 & 100.0 \\
\hline Diabetic retinopathy & 0 & 0.0 & 0 & 0.0 & 0 & 0.0 & 15 & 100.0 & 15 & 100.0 \\
\hline Hypertensive retinopathy & 0 & 0.0 & 0 & 0.0 & 0 & 0.0 & 9 & 100.0 & 9 & 100.0 \\
\hline Retinitis pigmentosa & 0 & 0.0 & 0 & 0.0 & 0 & 0.0 & 3 & 100.0 & 3 & 100.0 \\
\hline
\end{tabular}

TABLE 5: The recommended interventions for 621 patients seen at the low vision clinic of the Department of Optometry, University of KwaZulu-Natal.

\begin{tabular}{lcc}
\hline Device & $\boldsymbol{n}$ & $\mathbf{\%}$ \\
\hline Telescopes & 210 & 33.8 \\
Magnifiers & 184 & 29.6 \\
Protective measures (sunglasses or hats) & 152 & 24.5 \\
Counselling and referral to the school for the blind & 40 & 6.4 \\
Referral to an ophthalmologist & 23 & 3.7 \\
Referral to an occupational therapist & 12 & 1.9 \\
\hline
\end{tabular}

Note: Telescopes $(33.8 \%)$, magnifiers $(29.6 \%)$ and protective measures $(24.5 \%)$ were the most commonly recommended interventions for managing the conditions.

In this study, the proportion of females presenting at the low vision clinic was significantly higher than those of males $(p<0.05)$. Studies ${ }^{6,8}$ from other developing countries, however, suggest the opposite, with few females than males accessing and using low-vision eye care services. This could be because of the fact that low vision in developing countries is generally more common in females than in males and hence the increased uptake of services by the females. ${ }^{16}$ A significant proportion of patients were unemployed. This was an expected finding as the clinic essentially caters to the visual needs of indigent populations within the KwaZulu-Natal province.

There was a noticeable improvement in distance and near VA in many patients following low-vision assessment (Table 2). It is therefore important to make these devices available and affordable to those who need them. Eze et al. ${ }^{9}$ reported that $57.9 \%$ of the patients benefitted from low-vision aids at the UNTH. Leat et al. ${ }^{24}$ reported a much higher percentage $(89.5 \%)$ who benefitted by attending the clinic, and $81 \%$ were using low-vision devices regularly in Ontario, Canada. The differences observed in these studies could be related to the severity of the presenting VA. In this study, $86.6 \%$ with a presenting distance VA of worse than $1.3 \log$ MAR $(6 / 120)$ did not show any VA improvement after low-vision assessment. Khan ${ }^{23}$ conducted a retrospective study of lowvision patients in an Indian tertiary eye care hospital and reported that all the patients achieved a distance and near VA of $0.5 \log$ MAR $(6 / 18)$ and at least a $\log$ MAR of 0.5 , respectively. The difference between Khan's study ${ }^{23}$ and the present study could again be related to the initial presenting VA. For instance, in the present study, $61.9 \%$ had distance VA worse than $1.0 \log$ MAR, while in Khan's study ${ }^{23}$ only $29.9 \%$ had VA worse than $1.0 \log$ MAR. It therefore appears that worse presenting VA is associated with less chances of optical improvement following the use of low-vision assistive devices.

Albinism was the most common cause of low vision in those aged 0-50 years, possibly because of a high number of young patients presenting with the condition from special schools. Genetic counselling is suggested as a way to reduce this trend, as this service is freely available in the public hospitals of KwaZulu-Natal. Cataract was the second leading cause of low vision, indicating that preventable vision loss caused by cataract continues to cause most cases of low vision in adults aged 60 years and older. ${ }^{27}$ The general lack of eye care services, particularly low vision in the South African public health sector (which is accessed by the majority of citizens), could have affected this outcome. It is suggested that provision of eye care services be scaled up to cope with the increasing numbers to address avoidable vision loss. Richard ${ }^{6}$ also reported that cataract was one of the most common causes of low vision in a clinic-based study in Bayelsa State, Nigeria. Macular diseases ranked as the third most common cause of low vision, which may have been influenced by the fact that we included all maculopathies and ARMD under one category of macular diseases. Studies from developing countries such as Nigeria $^{8}$ and Ethiopia ${ }^{16}$ have reported retinitis pigmentosa and cataract to be the most common causes of low vision whilst those from developed countries such as the United States ${ }^{28}$ and Canada ${ }^{29}$ reported ARMD as the commonest cause of low vision. The discrepancies observed in these studies could possibly be because of differences in study areas and settings.

The commonest causes of low vision in patients aged 4-20 years in this study were amblyopia, albinism and corneal opacities. The high prevalence of amblyopia and corneal abnormalities could be a reflection of inadequate primary eye care services in this area. Gilbert and Ellwein ${ }^{13}$ and Eze et al. ${ }^{9}$ reported similar findings in Africa, whilst Olusanya et al. ${ }^{8}$ and $\mathrm{Khan}^{23}$ reported albinism, retinitis pigmentosa and hereditary macular diseases as common causes of low vision in Nigeria and India, respectively. Again, factors such as differences in study areas and settings may largely account for these observed discrepancies in the above-mentioned studies. The most common cause of low vision in patients 
aged 60 years and older was cataract, followed by macular diseases and glaucoma, suggesting that age-related diseases were predominant in the elderly patients. A recent systematic review and meta-analysis of the global causes of blindness and distance VI from 1990 to 2020 have shown that cataract, macular diseases and glaucoma were amongst the leading causes of low vision in sub-Saharan Africa. ${ }^{27}$ Cataract has been reported as the leading cause of blindness in South Africa, and has been identified as a national health priority. ${ }^{30}$ Although the government has undertaken a substantial campaign to reduce cataract blindness in South Africa in recent years, thousands still suffer from the condition because waiting lists for the procedure are long and many people do not realise that cataract blindness is, in the majority of cases, completely reversible. Cataract surgery is a simple, relatively painless, procedure to regain vision, and the high prevalence of this condition is a reflection of inadequate eye care services in this area. Glaucoma is the leading cause of irreversible blindness worldwide. ${ }^{27}$ Therefore, early diagnosis and treatment of glaucoma is important to reduce the risk of low vision.

Telescopes, magnifiers and protective measures were the most common interventions recommended for low-vision patients after assessment. Telescopes and magnifiers are useful for distance and near vision, respectively. For example, telescopes of varying magnification could be used for activities, such as sports, watching television and for viewing boards in classrooms. ${ }^{31,32}$ With the help of magnifiers, patients can view objects at arm's length or closer by manipulating magnification at variable working distances. ${ }^{10}$ The use of protective measures such as sunglasses and hats were most likely recommended for patients with albinism and those with cataract. People with albinism and those with cataract are sensitive to sunlight, and wearing sunglasses and hats limits their exposure to sunlight. Counselling and referrals to ophthalmologists and occupational therapists are also recommended for few low-vision patients as part of their rehabilitation.

This retrospective study has several limitations. Firstly, visual fields were not quantified in the record cards and were reported as either 'restricted' or 'full'. This limited their utility in defining low vision. These also suggest that gold standard visual field tests such as the Humphrey's were not performed at this low vision clinic. It is recommended that the Department of Optometry considers updating of their low-vision record cards to accurately capture the exact extent of visual field loss using equipment such as the Humphrey visual field test. Another limitation of this study is that acceptability and utilisation of low-vision devices were not evaluated because of its retrospective nature. In addition, these results cannot be extrapolated to the general population because it was a clinic-specific study, which may be influenced by various factors such as the source of referral to the low vision clinic. For example, the study included all patients who were seen at the low vision clinic as long as they met the stipulated criteria outlined in the methodology. However, some of these patients had presenting VA that did not fit into the definition of low vision. Because most of these patients were referred to the low vision clinic of UKZN from outside facilities, it suggests that those facilities failed to fully understand the definition of low vision. It is also possible that the patients were referred from facilities that did not have the requisite personnel to assess patients in order to make an appropriate referral to the low vision clinic of UKZN.

\section{Conclusion}

The majority of patients seen at the low vision clinic of UKZN are relatively young females. Visual acuity improves following optical low-vision aids assessment in many patients, particularly in those with residual vision better than $1.3 \log$ MAR (6/120). Most of the causes of low vision are largely preventable or avoidable and are similar to those reported in other studies under similar settings, although there are variations in the pattern of occurrence. Magnifiers and telescopes were the most frequently recommended low vision aids in this clinic.

\section{Acknowledgements}

The authors thank Dr V.N. Sukati for reviewing this article and giving valuable comments. They also thank Z.G. Dessie for providing statistical support.

\section{Competing interests}

The authors declare that they have no financial or personal relationships that may have inappropriately influenced them in writing this article.

\section{Authors' contributions}

Z.N.Q. and K.P.M. supervised the undergraduate research project conducted by honours students at the University of KwaZulu-Natal (all being co-authors). All students were involved in conceptualising, designing and undertaking the research and preparing the draft manuscript. The final version of the manuscript was prepared by Z.N.Q and K.P.M.

\section{Funding information}

This research received no specific grant from any funding agency in the public, commercial or not-for-profit sectors.

\section{Data availability statement}

Data sharing is not applicable to this article.

\section{Disclaimer}

The views and opinions expressed in this article are those of the authors and do not necessarily reflect the official policy or position of any affiliated agency of the authors. 


\section{References}

1. Blindness and $\mathrm{VI}$ prevention [homepage on the Internet]. World Health Organization; 2004 [cited 2018 Nov 12]. Available from: https://www.who.int/ blindness/causes/priority/en/index4.htm

2. World Health Organization. The management of low vision in children. Report of a WHO Consultation, Bangkok, July 1992, WHO/PBL/93.27. Geneva: World Health Organization; 1993.

3. Bourne RRA, Flaxman SR, Braithwaite T, et al. Magnitude, temporal trends, and projections of the global prevalence of blindness and distance and near VI: A projections of the global prevalence of blindness and distance and near VI: A
systematic review and meta-analysis. Lancet Glob Health. 2017;5(9):e888-e897.

4. Frick KD, Foster A. The magnitude and coast of global blindness: An increasing problem that can be alleviated. Am J Ophthalmol. 2003;135(4):471-476. https:// doi.org/10.1016/S0002-9394(02)02110-4

5. Resnikoff $S$, Pascolini D, Etya'ale $D$, et al. Global data on visual impairment in the year 2002. Bull World Health Organ. 2004;82(11):844-851.

6. Richard Al. Causes of blindness and low vision in Bayelsa state, Nigeria: A clinicbased study. Nig Q J Hosp Med. 2010;20(3):125-128.

7. Ogbonnaya CE. Profile of blindness and low vision at Ebonyi State University Teaching Hospital (EBSUTH) Abakaliki. Ebonyi Med J. 2012;11(1-2):13-19.

8. Olusanya B, Onoja G, Ibraheem W, Bekibele C. Profile of patients presenting at a low vision clinic in a developing country. BMC Ophthalmol [serial online]. 2012 [cited 2018 Nov 12];12:31. Available from: http://www.biomedcentral.com/14712415/12/31

9. Eze CC, Okoye Ol, Okoye O, Nwachukwu N, Okoloagu NN, Onwasigwe NE. Profile of low vision patients in a resource-poor underserved setting of a developing country. Open J Ophthalmol. 2018;8(2):120-131. https://doi.org/10.4236/ojoph. country. Op

10. Ackuaku-Dogbe EM, Abaidoo B, Braimah Zl, Afenyo G, Asiedu S. Causes of low vision and their management at Korle Bu Teaching Hospital, Accra, Ghana. J West Afr College Surg. 2016;6(3):105-122.

11. Ansah DO. Prevalence and causes of visual impairment among patients in Juaben Hospital Eye Clinic, Ghana. M J Opht. 2017;2(2):17.

12. Govender P, Ramson P, Visser L, Naidoo KS. Rapid assessment of avoidable blindness in the northern eThekwini district of KwaZulu-Natal Province, South Africa. Afr Vis Eye Health. 74(1):1-7. https://doi.org/10.4102/aveh.v74i1.15

13. Gilbert CE, Ellwein LB. Prevalence and causes of functional low vision in school-age children: Results from standardized population surveys in Asia, Africa, and Latin America. Invest Ophthalmol Vis Sci. 2008;49(3):877-881. https://doi.org/10.1167/ iovs.07-0973

14. Abdull MM, Sivasubramaniam S, Murthy GV, et al. Causes of blindness and visual impairment in Nigeria: The Nigeria National Blindness and Visual Impairment Survey. Invest Ophthalmol Vis Sci. 2009;50(9):4114-4120. https://doi.org/10.1167/ iovs.09-3507

15. Entekume G, Patel J, Sivasubramaniam S, et al. Prevalence, causes and risk factors for functional low vision in Nigeria: Results from the National Blindness and Visual Impairment Survey. Invest Ophthalmol Vis Sci. 2011;52(9):6714-6719. https:// doi.org/10.1167/iovs.11-7293
16. Melese M, Alemayehu W, Bayu S, et al. Low vision and blindness in adults in Gurage Zone, Central Ethiopia. Br J Ophthalmol. 2003:87(6):677-680. https://doi. org/10.1136/bjo.87.6.677

17. Kim JH, Joo KS, Moon NJ. Characteristics of 681 low vision patients in Korea. J Korean Med Sci. 2010;25(8):1217-1221. https://doi.org/10.3346/ jkms.2010.25.8.1217

18. Elliott DB, Trukolo-llic M, Strong JG, Pace R, Plotkin A, Bevers P. Demographic characteristics of the vision-disabled elderly. Invest Ophthalmol Vis Sci. 1997;38(12):2566-2575.

19. Wolffsohn JS, Cochrane AL. The changing face of the visually impaired: The Kooyong low vision clinic's past, present, and future. Optom Vis Sci. 1999;76(11):747-754. https://doi.org/10.1097/00006324-199911000-00023

20. Elliott DB, Strong G, Trukolo-llic M, Pace RJ, Plotkin A, Bevers P. A comparison of low vision clinic data with low vision survey and blindness registration information Optom Vis Sci. 1998;75(4):272-278. https://doi.org/10.1097/00006324 199804000-00024

21. Mohidin N, Yusoff S. Profile of a low vision clinic population. Clin Exp Optom. 1998;81(5):198-202. https://doi.org/10.1111/j.1444-0938.1998.tb06735.x

22. Paudel P, Khadka J, Sharma AK. Profile of a low vision population. Int Congr Ser 2005;1282:252-256. https://doi.org/10.1016/j.ics.2005.05.191

23. Khan SA. A retrospective study of low-vision cases in an Indian tertiary eye-care hospital. Indian J Ophthalmol. 2000;48(3):201-207.

24. Leat SJ, Rumney NJ. The experience of a university-based low vision clinic Ophthalmic Physiol Opt. 1990;10(1):8-15. https://doi.org/10.1111/j.1475-1313. 1990.tb01098.x

25. Sathyan S, Davis J, Antony R, Mathew S, Jyothi R. Demographic and clinical profile of patients presenting at the low vision clinic of a tertiary eye care facility in Kerala. Kerala J Ophthalmol. 2016;28(1):48-52. https://doi.org/10.4103/09766677.193866

26. Statistics South Africa. Mid-year population estimates [homepage on the Internet]. 2017 [cited 2018 Nov 12]. Available from: https://www.statssa. gov.za/publications/P0302/P03022017.pdf

27. Flaxman SR, Bourne RRA, Resnikoff $S$, et al. Global causes of blindness and distance vision impairment 1990-2020: A systematic review and meta-analysis. Lancet Glob Health. 2017;5(12):e1221-e1234.

28. Owsley C, McGwin G, Searcey K. Characteristics of low vision rehabilitation services in the United States. Arch Ophthalmol. 2009:127(5):681-689. https:// doi.org/10.1001/archophthalmol.2009.55

29. Maberley DA, Hollands H, Chang A, Adilman S, Chakraborti B, Kliever G. The prevalence of low vision and blindness in a Canadian inner city. Eye. 2007;21:528-533. https://doi.org/10.1038/sj.eye.6702257

30. Lecuona K, Cook C. South Africa's cataract surgery rates: Why are we not meeting our targets? S Med J. 2011;101(8):510-512.

31. Jackson AJ, Wolffsohn JSW. Low vision manual. Elsevier, Butterworth Heinemann. Oxford: United Kingdom; 2007.

32. Wolffsohn JS, Peterson RC. A review of current knowledge on Electronic Vision Enhancement Systems for the visually impaired. Ophthalmic Physiol Opt. 2003; 23(1):35-42. 